\title{
Application of markers of collagen metabolism in serum and synovial fluid for assessment of disease process in patients with rheumatoid arthritis
}

\author{
Markku Hakala, Sari Åman, Reijo Luukkainen, Leila Risteli, Markku Kauppi, \\ Pentti Nieminen, Juha Risteli
}

\begin{abstract}
Objective-To assess the potential of markers of collagen metabolism to reflect disease processes in rheumatoid arthritis (RA).
\end{abstract}

Methods-Serum (S) and synovial fluid (SF) from 59 patients with $R A$, and a knee joint effusion and serum from 90 control subjects were studied with radioimmunoassays for the aminoterminal propeptides of type I and type III procollagens (PINP and PIIIN, respectively). The breakdown of type I collagen was quantified with a radioimmunoassay for the cross linked carboxyterminal telopeptide of type I collagen (ICTP).

Results-About $50 \%$ of the patients had increased S-ICTP and S-PIIINP values, whereas S-PINP was increased in only $20 \%$ of the patients. The mean SF:S ratios of these markers varied between 4 (for ICTP) and 340 (for PIINP), indicating that markers of collagen metabolism are formed locally and then released into the circulation. SF-PINP and SF-PIIINP correlated with each other $\left(r_{\mathrm{s}}=0.86\right.$, $\mathrm{p}<0.001)$ and with SF-ICTP $\left(r_{\mathrm{s}}=0.69\right.$, $\mathrm{p}<0.001$, and $r_{\mathrm{s}}=0.65, \mathrm{p}<0.001$, respectively). SF-ICTP was clearly related to radiographic findings in the corresponding knee joint, patients with gross bone deformation having the greatest SF-ICTP concentrations. S-ICTP and S-PIINP also correlated with conventional markers of disease activity, such as $\mathrm{C}$ reactive protein and joint swelling score.

Conclusion-Markers of collagen metabolism both in serum and synovial fluid can be measured to provide an assessment of disease process in patients with RA. ICTP and PIIINP are the most informative.

(Ann Rheum Dis 1995; 54: 886-890)

The disease process in patients with rheumatoid arthritis (RA) is usually assessed by so-called markers of disease activity, such as number of swollen joints, erythrocyte sedimentation rate (ESR) and concentration of $C$ reactive protein (CRP) in blood, in addition to radiographic evidence. ${ }^{1-4}$ However, much research is focused on finding biochemical assays which could more accurately reflect the pathological processes in the joints..$^{5-7}$ Among such tests are those measuring the synthesis and breakdown of different types of collagen. ${ }^{5-8}$

We have shown previously that the average serum concentration of the cross linked carboxyterminal telopeptide of type I collagen (S-ICTP) was greater in patients with RA than in controls, and the greatest S-ICTP values were seen in patients with signs of aggressive joint disease. ${ }^{9}$ An increased S-ICTP concentration in early $\mathrm{RA}$ is a recognised risk factor for a more erosive disease course. ${ }^{10}$ The assay used measures the breakdown of mature cross linked type I collagen. ${ }^{11}$ Similar results have been found in RA with respect to the concentration of the aminoterminal propeptide of type III procollagen in serum (S-PIINN), ${ }^{12}{ }^{13}$ which is a marker of type III collagen synthesis. ${ }^{14}$ Inflammatory synovial fluid (SF) contains large amounts of PIIINP. ${ }^{15}{ }^{16}$ The high SF:S-PIINP ratios found in such patients suggest local production and release of the protein from the joint into the circulation. ${ }^{16}$

The aim of the present study was to examine the relationship between the degradative and synthetic processes involving type I and type III collagen in RA, and the patients' clinical state. We assessed collagen metabolism by measuring the concentrations of ICTP, PIINP, and the aminoterminal propeptide of type I procollagen (PINP) (manuscript in preparation). The last of these is a newly developed assay of type I collagen synthesis. For comparison of the serum and synovial fluid concentrations of these substances, patients with RA and a knee joint effusion were included in the study.

\section{Patients and methods}

PATIENTS AND CONTROLS

We studied 59 unselected patients (39 of them women) undergoing treatment for $\mathrm{RA}^{17}$ and a knee joint effusion in outpatient or inpatient departments of three rheumatism hospitals in Finland. Mean age of the 59 patients was $58 \cdot 1$ (SD 13.5) years (range 19-82) and mean duration of disease $13.5(11.6)$ years (range $0 \cdot 5-58)$. Forty six $(78 \%)$ of the patients were being treated with disease modifying antirheumatic drugs (DMARDs) and 28 (47\%) with peroral corticosteroid therapy at the time of the study. Forty nine patients $(83 \%)$ had previously received one or more intra-articular injections of corticosteroids into the knee joint under study: in 23 cases the time between the last intra-articular injection of corticosteroids and the sampling of the synovial fluid was less 
than or equal to six months, and in 12 of them it was less than or equal to three months. Ninety subjects without any signs of joint or metabolic bone disease, recruited from the area around Oulu, Northern Finland, formed the control group; their mean age was 58.8 (11.2) years (range $32-83$ ), and $59(66 \%)$ of them were women.

CLINICAL, LABORATORY AND RADIOGRAPHIC EXAMINATIONS

The physical examination included the Ritchie articular index $(\mathrm{RAI})^{18}$ and a joint swelling score (none $=0, \operatorname{mild}=1$, moderate $=2$, severe $=3$ ), both assessed as sum of the scores of individual joints or joint groups.

Routine laboratory tests for the assessment of the disease activity were also performed. All joint aspirations were made for therapeutic reasons. The synovial fluids were collected in sterile tubes and stored at $-20^{\circ} \mathrm{C}$, together with serum samples obtained at the same time. The synovial fluid samples were not centrifuged.

The erosive state of the knee joints was assessed by one of the authors (RL) using Larsen's method, ${ }^{19}$ comparing posteroanterior radiographs with a standard series. Larsen index scores are: $0=$ normal; $1=$ slight $a b-$ normality with one or more minor lesions (periarticular soft tissue swelling, periarticular osteoporosis, and slight joint space narrowing); 2 = definite early abnormality with erosion (not obligatory) and joint space narrowing; $3=$ medium destructive abnormality (erosion obligatory); 4 = severe destructive abnormality (bone deformation present); $5=$ mutilating abnormality (gross bone deformation).

MARKERS OF COLLAGEN METABOLISM

ICTP, PINP, and PIIINP were measured, respectively, in duplicate 100,50 , and $200 \mu l$ aliquots of serum, of undiluted SF in the case of ICTP, and of appropriately diluted (using assay buffer) SF in the case of the procollagen propeptides. Equilibrium radioimmunoassays for the human antigens were used, ${ }^{10} 14$ with reagents supplied by Orion Diagnostica (FIN90460 Oulunsalo, Finland). The intra-assay and interassay coefficients of variation of the three markers tested with human serum samples are less than $10 \% .^{1014}$ Intra-assay variation for SF samples was $4.4 \%$ for PINP and $5.7 \%$ for PIIINP. The effect of centrifugation on the ICTP and PIIINP contents of SF was tested on samples from five patients. An aliquot of each sample was centrifuged within one hour after aspiration at $1800 \mathrm{~g}$, for two periods of 20 minutes.

STATISTICAL ANALYSIS

The data were recorded and calculated on a personal computer using SOLO statistical software. ${ }^{20}{ }^{21}$ Mann-Whitney test, $\chi^{2}$ statistics, Fisher's exact probability test, Spearman's rank correlation coefficient test, and analysis of variance were used as appropriate.
Table 1 Mean (SD) concentrations of three markers of collagen metabolism in the serum of 59 patients with rheumatoid arthritis $(R A)$ and 90 controls

\begin{tabular}{|c|c|c|c|}
\hline & $R A$ patients & & Controls \\
\hline \multirow{6}{*}{$\begin{array}{l}\text { S-ICTP }(\mu g / 1) \\
\text { Value }>(\text { mean }+2 S D) \\
\text { (\% of patients) } \\
\text { S-PNPP }(\mu g / 1)+ \\
\text { Value }>(\text { mean }+2 S D) \\
\text { (\% of patients) } \\
\text { S-PIIINP }(\mu g / 1) \dagger \\
\text { Value }>(\text { mean }+2 S D) \\
(\% \text { of patients) }\end{array}$} & $6 \cdot 4(4 \cdot 1)$ & $\star \star \star$ & $3.1(0.8)$ \\
\hline & & & \\
\hline & $48 \cdot 1(21 \cdot 8)$ & $\star \star$ & $36.8(15 \cdot 6)$ \\
\hline & & & \\
\hline & $5 \cdot 3(2 \cdot 7)$ & $\star \star \star \star$ & $3.3(0.8)$ \\
\hline & 42 & & \\
\hline
\end{tabular}

tTested in 57 patients.

S-ICTP = Serum cross-linked carboxyterminal telopeptide of type I collagen; S-PINP and S-PIINP = serum aminoterminal type I collagen; S-PINP and S-P III Procollagens, respectively. pᄎ $\mathrm{p}<0.01, \star \star \star \mathrm{p}<0.001$, between groups.

\section{Results}

Centrifugation was found to decrease the levels of the markers of collagen metabolism in SF to the same extent as occurs with centrifugation of plasma to separate serum. With the exception of one sample each, the level of the markers after centrifugation, was decreased compared with native samples, by amounts varying from 6.3 to $11.7 \%$ for SF-ICTP and from $0 \cdot 2$ to $10 \cdot 4 \%$ for SF-PIINP.

Table 1 shows the mean concentrations of the three markers of collagen metabolism in the sera of the patients with RA and in the controls. More than $50 \%$ of the patients had increased S-ICTP concentrations, and nearly $50 \%$ had increased S-PIINP; in contrast, only $19 \%$ of the patients had increased S-PINP concentrations. In all but one of the patients, the concentrations of individual markers were greater in SF than in serum. In the single exception having an S-ICTP value somewhat greater than the corresponding SF measurement, both concentrations were low. The median ( $\mathrm{SD}$, range) SF concentrations were ICTP $16 \cdot 7(18 \cdot 1,2 \cdot 8-96.9) \mu \mathrm{g} /$, PINP $782(903,118-5017) \mu \mathrm{g} / \mathrm{l}$, and PIIINP 1478 $(857,278-4781) \mu g /$. The SF:S ratios for the individual markers of collagen metabolism were $4.0(95 \%$ confidence interval (CI) 3.3-4.8) for ICTP, $25 \cdot 2(95 \%$ CI 19.7-30.8) for PINP, and 340 (95\% CI 295-385) for PIIINP.

Because the volume of a joint effusion can change rapidly, making the assessment of concentrations inappropriate, we also calculated the values as ratios of one compound to another, and obtained: $59.4 \quad(95 \% \mathrm{CI}$ 44.7-74.1) for SF-PINP:SF-ICTP, 95.1 (95\% CI 74.2-116) for SF-PIIINP:SF-ICTP, and $1.9(95 \%$ CI 1.6-2.3) for SF-PIINP:SF-PINP. Table 2 shows the ratios of the markers in relation to the radiographic state (Larsen index) of the corresponding joint.

Table 2 Mean (SE) ratios of the three markers of collagen metabolism in synovial fluid in relation to radiographic findings in the joint (Larsen index)

\begin{tabular}{llrl}
\hline Larsen index & Marker ratio & & \\
\cline { 2 - 4 } & PINP:ICTP & PIIINP:ICTP & PIIINP:PINP \\
\hline $0-1$ & $71 \cdot 3(14 \cdot 9)$ & $120.4(21 \cdot 0)$ & $1 \cdot 7(0 \cdot 4)$ \\
2 & $61 \cdot 1(12 \cdot 4)$ & $95 \cdot 2(17 \cdot 6)$ & $2 \cdot 1(0 \cdot 3)$ \\
3 & $61 \cdot 8(15 \cdot 4)$ & $92.9(21 \cdot 8)$ & $2 \cdot 1(0 \cdot 4)$ \\
$4-5$ & $36 \cdot 2(17 \cdot 6)$ & $62 \cdot 2(24 \cdot 9)$ & $1 \cdot 7(0 \cdot 4)$ \\
\hline
\end{tabular}


Table 3 Correlations between concentrations of the three markers of collagen metabolism in synovial fluid (SF) and serum (S) of patients with rheumatoid arthritis

\begin{tabular}{|c|c|c|c|c|c|c|c|}
\hline & & \multicolumn{3}{|c|}{ Synovial fluid } & \multicolumn{3}{|l|}{ Serum } \\
\hline & & $I C T P$ & PINP & PIIINP & ICTP & PINP & PIIINP \\
\hline SF-PINP & $\begin{array}{l}r_{\mathrm{s}} \\
\mathrm{p}\end{array}$ & $\begin{array}{c}0.69 \\
<0.001\end{array}$ & & & & & \\
\hline SF-PIIINP & $\begin{array}{l}r_{s} \\
\mathrm{p}\end{array}$ & $\begin{array}{c}0.65 \\
<0.001\end{array}$ & $\begin{array}{c}0.86 \\
<0.001\end{array}$ & & & & \\
\hline S-ICTP & $\begin{array}{l}r_{s} \\
\mathrm{p}\end{array}$ & $\begin{array}{c}0.55 \\
<0.001\end{array}$ & $\begin{array}{l}0.32 \\
0.016\end{array}$ & $\begin{array}{l}0.34 \\
0.010\end{array}$ & & & \\
\hline S-PINP & $r_{s}$ & $\begin{array}{l}0.42 \\
0.001\end{array}$ & $\begin{array}{l}0.29 \\
0.027\end{array}$ & $\begin{array}{l}0.33 \\
0.013\end{array}$ & $\begin{array}{c}0.50 \\
<0.001\end{array}$ & & \\
\hline S-PIIINP & $\begin{array}{l}r_{\mathrm{s}} \\
\mathrm{p}\end{array}$ & $\begin{array}{c}0.54 \\
<0.001\end{array}$ & $\begin{array}{l}0.39 \\
0.003\end{array}$ & $\begin{array}{l}0.39 \\
0.003\end{array}$ & $\begin{array}{c}0.81 \\
<0.001\end{array}$ & $\begin{array}{c}0.53 \\
<0.001\end{array}$ & \\
\hline
\end{tabular}

Table 3 gives the correlations observed between the levels of the various markers of collagen metabolism in serum and synovial fluid of patients. In serum, the closest correlation was between PIINN and ICTP, and in synovial fluid it was that between PINP and PIINP. In addition, the two markers of synthesis had clear correlations with SF-ICTP. A significant correlation was found also between the synovial fluid and serum concentrations of each of the individual markers.

In the controls, the following correlations were found between the serum concentrations of the markers of collagen metabolism: $r_{\mathrm{s}}=0.48, \mathrm{p}<0.001$ for PINP $v$ ICTP; $r_{\mathrm{s}}=0.51, \mathrm{p}<0.001$ for PIIINP $v$ ICTP; $r_{\mathrm{s}}=0.34, \mathrm{p}=0.001$ for PINP $v$ PIINN. The balance of type I collagen metabolism, assessed by the ratio (mean (SD)) of S-PINP:S-ICTP, was in favour of degradation in patients compared with controls: $9.4(5.4)$ and $12 \cdot 1$ $(4.9)$, respectively $(p<0.001)$.

Table 4 shows the correlations between indicators of disease activity and those of collagen metabolism. Both S-ICTP and S-PIINP showed positive correlations with disease activity markers. None of the markers in SF correlated with the total number of leucocytes or with the number of polymorphonuclear leucocytes in SF.

Seven of the 39 female patients were premenopausal and 32 were postmenopausal. S-PINP values did not differ according to menopausal state, but increased S-ICTP and S-PIIINP concentrations were more common among the postmenopausal women, who more often had signs of active disease (increased CRP values and high joint swelling scores) that are known to be associated both with increased S-ICTP and S-PIIINP.

Table 4 Correlations between markers of disease activity and collagen metabolism in patients with rheumatoid arthritis

\begin{tabular}{lcccc}
\hline $\begin{array}{l}\text { Marker of disease } \\
\text { activity }\end{array}$ & \multicolumn{3}{c}{ Marker of collagen metabolism } \\
\cline { 2 - 5 } & & S-ICTP & S-PINP & S-PIINP \\
\hline ESR & $r_{\mathrm{s}}$ & 0.43 & -0.07 & 0.23 \\
& $\mathrm{p}$ & $<0.001$ & $\mathrm{NS}$ & $\mathrm{NS}$ \\
CRP & $r_{\mathrm{s}}$ & 0.59 & 0.09 & 0.48 \\
& $\mathrm{p}$ & $<0.001$ & $\mathrm{NS}$ & $<0.001$ \\
Ritchie index & $r_{\mathrm{s}}$ & 0.46 & 0.06 & 0.37 \\
& $\mathrm{p}$ & $<0.001$ & $\mathrm{NS}$ & 0.005 \\
Joint swelling score & $r_{\mathrm{s}}$ & 0.65 & 0.21 & 0.60 \\
& $\mathrm{p}$ & $<0.001$ & $\mathrm{NS}$ & $<0.001$ \\
\hline
\end{tabular}

$\overline{\mathrm{ESR}}=$ Erythrocyte sedimentation rate; $\mathrm{CRP}=\mathrm{C}$ reactive protein.
Figures 1 and 2 show the relationship between levels of markers of collagen metabolism and the erosive state of the knee joint (Larsen index). SF-ICTP showed the closest relation with the Larsen index (analysis of variance: $p<0.001$ ) (fig 1 ). The mean SF-ICTP concentrations in the Larsen index groups $0-1,2,3$, and 4-5 were $14 \cdot 7,17 \cdot 5$, $22 \cdot 7$, and $43.6 \mu \mathrm{g} / \mathrm{l}$ respectively; that in the combined Larsen group 4-5 differed significantly from that in the other groups ( $p<0.05$ in multiple comparisons). The corresponding values for SF-PIINP were 1305, 1314, 2058 and $2023 \mu \mathrm{g} / \mathrm{l}(\mathrm{p}=0.014)$, SF-PIIINP in both Larsen groups 3 and 4-5 differing significantly from that in groups $0-1$ and 2 ( $\mathrm{p}<0.05$ in multiple comparisons). The mean SF-PINP concentrations were $821 \mu \mathrm{g} / 1$ in Larsen group $0-1,885 \mu \mathrm{g} / \mathrm{l}$ in group 2, $1531 \mu \mathrm{g} / \mathrm{l}$ in group 3 and $1353 \mu \mathrm{g} / \mathrm{l}$ in group 4-5 (NS).

S-ICTP and S-PIINP values were significantly lower in patients currently receiving a DMARD compared with those not taking these drugs: mean values were 5.7 (3.9) $\mu \mathrm{g} / 1$ $v 8.6(4.4) \mu \mathrm{g} / \mathrm{l}$ for S-ICTP $(\mathrm{p}=0.010)$, and $4.7(1.9) \mu \mathrm{g} / 1 v 7.3(3.9) \mu \mathrm{g} / \mathrm{l}$ for S-PIINP $(p=0.021)$. The corresponding values for S-PINP were $44.5 \quad(18.7) \quad \mu g / 1 \quad v \quad 61.5$ $(28 \cdot 0) \mu g / 1(p=0.055)$. No significant differences in mean serum levels of the markers were found in patients taking or not taking peroral corticosteroids, but SF levels of all the markers were significantly greater in patients taking peroral corticosteroids compared with those not receiving this treatment. The explanation of this may be multifactorial, but patients treated with oral corticosteroids significantly more often had higher Larsen indexes in the knee under study than did those not taking these drugs. There was an association between the time elapsed since the last intra-articular injection of corticosteroids and SF-ICTP levels $(p=0.007)$; patients receiving a recent intraarticular injection more often had lower levels of the marker.

\section{Discussion}

Markers of collagen synthesis and degradation measured in serum and synovial fluid reflect the grade of synovitis and tissue breakdown in RA. In this study we used assays for markers of the synthesis and degradation of type I collagen (PINP and ICTP) and for the synthesis of type III collagen (PIINP). Type I collagen is the most abundant protein species in the human body. Most of it is present in bones, where it accounts for about $90 \%$ of the organic matrix, and it is also the major matrix protein in tendons, ligaments, and soft connective tissues. Type III collagen is the second most abundant collagen type and is found in soft connective tissues. High concentrations of all these collagen derived substances were found in synovial fluid, and their concentrations correlated with the grade of destruction in the joint. The high SF:S ratios, in particular for PIINP and PINP, suggest that these antigens are formed locally 


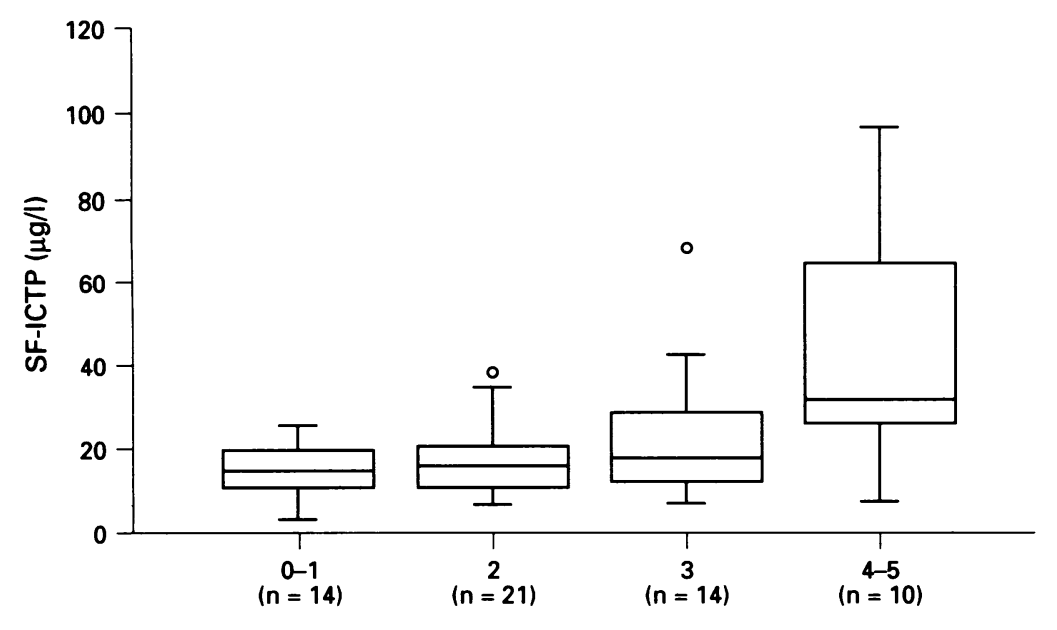

Larsen index

Figure 1 Relation between concentration of cross linked carboxyterminal telopeptide of type I collagen in synovial fluid (SF-ICTP) and the erosive state (Larsen index) of the joint in 59 patients with rheumatoid arthritis (analysis of variance: $p<0.001$ ). Box plot: horizontal line = median value of the variable; lower (and upper) lines indicate the 25th (75th) and 10th (90th) centiles, respectively. Small circles represent outliers.

in the inflamed joints and then released into the circulation. Jensen et $a l^{22}$ investigated the transport of PIIINP from the knee cavity into the circulation in conscious pigs after intraarticular injection of radiolabelled PIIINP. Sequential sampling of thoracic duct lymph, serum, and urine suggested that PIIINP is most probably transported from the joint space by bulk flow. Degradation in the lymphatics cannot be excluded completely, but a major part of PIINNP reaches the thoracic duct, and thereby the circulation, in the intact form.

In the present study, concentrations of S-PIIINP and S-ICTP were increased in about $50 \%$ of the patients, and also correlated with markers of disease activity such as CRP and the joint swelling score, these results being in accordance with earlier findings. ${ }^{910} 1323$ In contrast S-PINP was increased in only a minority of the patients and did not correlate with disease activity. It is probable that, though PINP is released freely from the joints, the amount is small in comparison with that released from the skeleton.

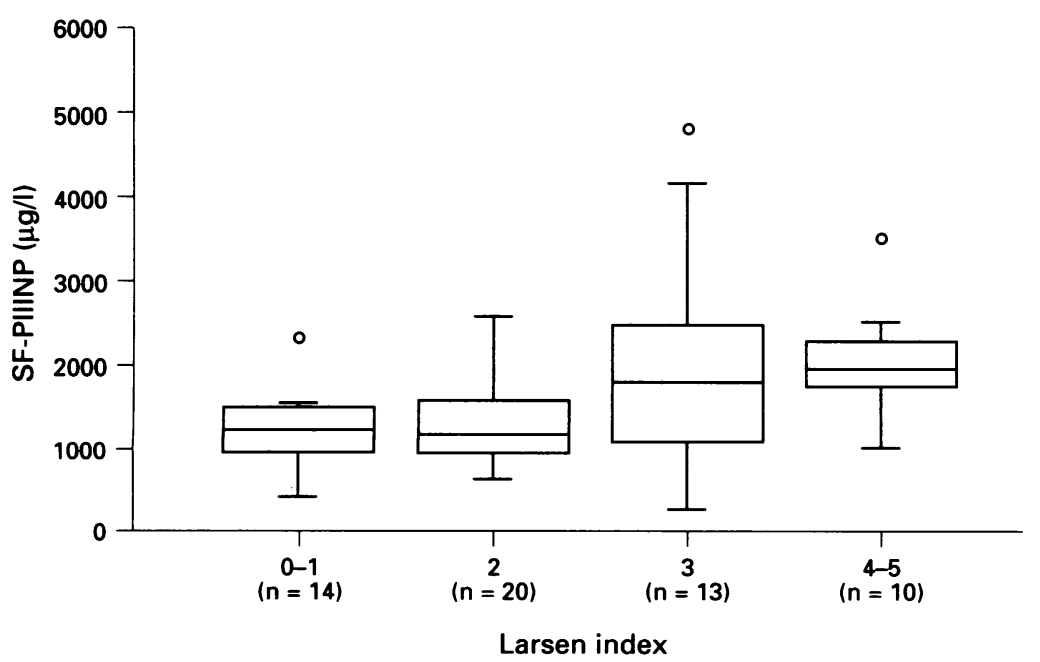

Figure 2 Relation between concentration of aminoterminal propeptide of type III procollagen in synovial fluid (SF-PIINP) and the erosive state of the joint in 57 patients with rheumatoid arthritis (analysis of variance: $p=0.014$ ). Box plot as in figure 1 . Small circles represent outliers.
A shift in the balance of type I collagen metabolism in RA towards the direction of collagen breakdown was demonstrated by the decreased ratio S-PINP:S-ICTP in patients compared with control subjects. Similarly, a low rate of type I collagen synthesis, assessed by the carboxyterminal propeptide of type I procollagen (PICP) in serum, has been reported previously in RA. ${ }^{24}$

SF-PINP and SF-PIIINP concentrations correlated strongly. The synthesis of both type I and type III collagen is obviously increased in the synovial tissue of a rheumatoid joint, from where the propeptides are released into SF. A high grade synovitis in a rheumatoid joint is usually accompanied by a destructive process in the joint. Accordingly, SF-PINP and SF-PIIINP showed a clear correlation with SF-ICTP. The assessment of synovial fluid constituents as concentrations is, however, somewhat inaccurate; there is a bidirectional fluid flux across the synovial lining, ${ }^{25}$ and the amount of effusion may vary rapidly. This is why we also compared the ratios between various markers with the radiographic findings in the joint. The ratios suggested more collagen synthesis in cases with less radiographic damage, and more collagen degradation in cases with more severe radiographic damage.

Radiographic images record past destructive activity in RA, while the markers of collagen metabolism in SF reflect the current balance between destructive and reparatory processes. SF-ICTP correlated most closely with the joint destruction. However, SF-ICTP showed a large variation in higher Larsen index groups, reflecting the varying activity of collagen degradation. It is evident that the markers of collagen metabolism, such as SF-ICTP or the ratio SF-PINP:SF-ICTP, provide information on the disease process in the joint additional to that obtained from radiographs alone.

In interpreting our results, certain confounding factors which might have influenced the results should be considered. Previous intra-articular injections are among the most important, and in our group there were some patients treated recently in this way. In addition, we found that serum levels of the markers of collagen metabolism were lower in patients currently taking DMARDs than in those not receiving these drugs. Our crosssectional study was not planned to investigate the effect of treatments on these markers. However, some longitudinal studies found that S-PIIINP and S-ICTP decrease more slowly than the acute phase reactants after commencement of DMARDs. ${ }^{1013}$ It should be noted also that biological variation in the serum level of these markers of collagen metabolism is about $20-25 \%$, the least significant change for an individual being smaller than that for corresponding urinary markers (up to $50 \%$ ). ${ }^{26}$ To be useful in the follow up of individual patients in clinical practice, the change in concentration of a marker in response to treatment should exceed the least significant change. Further longitudinal studies are required to clarify this question. 
As the markers of collagen metabolism are not tissue specific, it is not possible to trace their origin in synovial fluid. However, the results of the present study and of earlier reports $^{13} 1516$ suggest that PIINP and PINP are synthesised in synovial tissue. A strong correlation between these two propeptides and their stable ratio regardless of the degree of radiological damage in the knee joint suggest that most of the SF-PINP is derived from synovial tissue, and only a small part from the articular bone. SF-ICTP, a breakdown product of type I collagen, may reflect the degradation of this collagen in synovial tissue, joint capsule, and ligaments, while necrotic areas may be found in active synovitis, sometimes shown as 'rice bodies' in synovial fluid. However, type I collagen is most abundant in mineralised bone, and in our patients with the highest Larsen index scores of the knee joint, indicating destructive disease, and with high SF-ICTP levels, most of the ICTP was most probably derived from articular bone.

This work was supported in part by grants from Yrjö Jahnsson Foundation, the Medical Research Council of the Academy of Finland, Helsinki, and the Rheumatism Research Foundation, Heinola, Finland.

The authors gratefully acknowledge the expert technical assistance of Ms Kristiina Pekkala and Ms Ulla Pohjoisaho.

1 Gabriel S E, Luthra H S. Rheumatoid arthritis: can the long-term outcome be altered? May Clin Proc 1988; 63: 58-68.

2 Kushner I. C-reactive protein in theumatology. Arthritis Rheum 1991; 34: 1065-8.

3 Sharp J T. Radiologic assessment as an outcome measure in rheumatoid arthritis. Arthritis Rheum 1989; 32: 221-9.

4 Brower A C. Use of the radiograph to measure the course of rheumatoid arthritis. Arthritis Rheum 1990; 33: 316-24.

5 Peel N, Eastell R, Russell G. Markers of bone and collagen breakdown in early inflammatory arthritis. Ballières Clin Rheumatol 1992; 6: 351-72.

6 Poole A R. Immunochemical markers of joint inflammation, skeletal damage and repair: where are we now? $A n n$ Rheum Dis 1994; 53: 3-5.

7 Wollheim F A. New insights into joint damage from analysis of released biochemical markers. Br $\mathcal{F}$ Rheumatol 1994; 33: $1-4$.

8 Taylor A K, Lueken S A, Libanati C, Baylink B J. Biochemical markers of bone turnover for the clinical assessment of bone metabolism. Rheum Dis Clin N Am 1994; 20: 589-607.

9 Hakala M, Risteli L, Manelius M, Nieminen P, Risteli J. Increased type I collagen degradation correlates with disease severity in theumatoid arthritis. Ann Rheum Dis 1993; 52: 866-9.
10 Paimela L, Leirisalo-Repo M, Risteli L, Hakala M, Helve T, Risteli J. Type I collagen degradation product in serum of patients with early rheumatoid arthritis: relationship to disease activity and radiological progression in a 3-year follow-up. Br $\mathcal{f}$ Rheumatol 1994; 33: 1012-6.

11 Risteli J, Elomaa I, Niemi S, Novamo A, Risteli L. Radioimmunoassay for the pyridinoline cross-linked carboxyterminal telopeptide of type I collagen: a new serum marker of bone collagen degradation. Clin Chem 1993; 39: 635-40.

12 Hørslev-Petersen K, Bentsen K D, Junker J, Lorenzen I. Serum amino-terminal type III procollagen peptide in rheumatoid arthritis. Relationship to disease activity, treatment, and development of joint erosions. Arthritis treatment, and developm

13 Hørslev-Petersen K, Bentsen K D, Engström-Laurent A, Junker P, Halberg P, Lorenzen I. Serum amino terminal type III procollagen and serum hyaluronan in rheumatoid arthritis: relation to clinical and serological parameters of inflammation during 8 and 24 months' treatment with levamisole, penicillamine, or azathioprine. Ann Rheum Dis 1988; 47: 116-26.

14 Risteli J, Niemi S, Trivedi $P$, Măentausta $O$, Mowat A P, Risteli L. Rapid equilibrium radioimmunoassay for the amino-terminal propeptide of human type III procollagen. Clin Chem 1988; 34: 715-8.

15 Gressner A M, Neu H-H. N-terminal procollagen peptide and $\beta_{2}$-microglobulin in synovial fluids from inflammatory and non-inflammatory joint diseases. Clin Chim matory and non-inflam $1984 ; 141: 241-5$.

16 Hørslev-Petersen $\mathrm{K}$, Saxne $\mathrm{T}$, Haar $\mathrm{D}$, et al. The aminoterminal-type-III procollagen peptide and proteoglycans in serum and synovial fluid of patients with rheumatoid arthritis or reactive arthritis. Rheumatol Int 1988; 8: 1-9.

17 Amett F C, Edworthy S M, Bloch D A, et al. The American Rheumatism Association 1987 revised criteria for the classification of theumatoid arthritis. Arthritis Rheum 1988; 31: 315-24.

18 Ritchie D M, Boyle J A, McInnes J M, et al. Clinical studies with an articular index for the assessment of joint tenderness in patients with rheumatoid arthritis. $Q \mathcal{F} M e d$ tenderness in patients

19 Larsen A, Dale K, Eek M. Radiographic evaluation of rheumatoid arthritis and related conditions by standard reference films. Acta Radiol Diagn 1977; 18: 481-91.

20 SOLO user's guide. Version 2.0. Los Angeles: BMDP Statistical Software Inc, 1988; 1-266.

21 SOLO advanced set. Version 2.0. Los Angeles: BMDP Statistical Software Inc, 1988; 1-92.

22 Jensen L T, Henriksen J H, Olesen H P, Risteli J, Lorenzen I. Lymphatic clearance of synovial fluid in conscious pigs: the aminoterminal propeptide of type III procollagen. Eur $\mathcal{Y}$ Clin Invest 1993; 23: 778-84.

23 Kotaniemi A, Isomăki H, Hakala M, Risteli L, Risteli J. Increased type I collagen degradation in early rheumatoid Increased type I collagen degradation in
arthritis. 7 Rheumatol 1994; 21: 1593-6.

24 Kröger H, Risteli J, Risteli L, Penttilă I, Alhava E. Serum osteocalcin and carboxyterminal propeptide of type I procollagen in rheumatoid arthritis. Ann Rheum Dis 1993; 52: $338-42$.

25 McDonald J N, Levick J R. Evidence for simultaneous bidirectional fluid flux across synovial lining in knee joints of anaesthetized rabbits. Exp Physiol 1992; 77: 513-5.

26 Blumsohn A, Hannon R A, Al-Dehaimi A W, Eastell R. Short-term intraindividual variability of markers of bone turnover in healthy adults. $\mathcal{F}$ Bone Miner Res 1994; 9 (suppl 1): S153. 